\title{
Collaboration patterns, external shocks and uncertainty: Swiss nuclear energy politics before and after Fukushima
}

\author{
Manuel Fischer
}

ACCEPTED FOR PUBLICATION AT “ENERGY POLICY”

\begin{abstract}
Energy shocks like the Fukushima accident can have important political consequences. This article examines their impact on collaboration patterns between collective actors in policy processes. It argues that external shocks create both behavioral uncertainty, meaning that actors do not know about other actors' preferences, and policy uncertainty on the choice and consequences of policy instruments. The context of uncertainty interacts with classical drivers of actor collaboration in policy processes. The analysis is based on a dataset comprising interview and survey data on political actors in two subsequent policy processes in Switzerland and Exponential Random Graph Models for network data. Results first show that under uncertainty, collaboration of actors in policy processes is less based on similar preferences than in stable contexts, but trust and knowledge of other actors are more important. This complicates the formation of stable actors coalitions, which can be both an advantage or a threat to policy-makers. Second, under uncertainty, scientific actors are not preferred collaboration partners.
\end{abstract}

\section{Keywords}

External shocks, uncertainty, policy-making, collaboration, Exponential Random Graph Model.

This document is the accepted manuscript version of the following article:

Fischer, M. (2015). Collaboration patterns, external shocks and uncertainty: Swiss nuclear energy politics before and after Fukushima. Energy Policy, 86, 520-528. https://doi .org/10.1016/j.enpo1 .2015.08.007 


\section{Introduction}

Energy shocks such as the Fukushima accident in 2011 can have far-reaching consequences on several levels. On the level of individuals, the nuclear accident in Japan led to lower energy consumption (Wakiyama et al. 2014), as well as changed the risk perception of nuclear energy and decreased its acceptance among the general public (Kim et al. 2013; Siegrist et al. 2014; Siegrist and Visschers 2013). On the level of countries, and partly as a consequence of the decreased acceptance among the public, the accident led to initiatives for policy change towards nuclear-free energy production in several countries. Indeed, external shocks such as the Fukushima accident are an important explanation for policy change in public policy theories (Grossman 2015; Grossmann 2012; Nohrstedt 2005; Sabatier and Jenkins-Smith 1993). External shocks influence policy images of the public as well as of collective political actors (Baumgartner and Jones 1993; Hall 1993), i.e. they put into question existing policies and complicate the elaboration of future policies. Yet, little is known about the behavior of collective political actors such as parties, interest groups, or administrative agencies in policy processes taking place after external shocks. External shocks create uncertainties for actors, as they have to deal with new issues, new images, and new policy solutions. This paper examines the collaboration behavior of actors in energy policy processes. It studies a policy process before the Fukushima accident with relatively low uncertainty, and a policy process after the Fukushima accident with higher uncertainty. Understanding collaboration patterns within policy processes is crucial (Ingold and Fischer 2014). It allows insight into mechanisms by which collective political actors negotiate new policies. The literature shows that, for example, preference similarity or perceived power explain collaboration between political actors (e.g. Berardo 2013; Gerber et al. 2013; Henry 2011; Ingold 2011; Leifeld and Schneider 2012). However, incentives for collaboration among actors also depend on whether a policy process evolves in a context of uncertainty or, on the contrary, in a stable and certain environment (Newig et al. 2005; Sigel et al. 2010). 
After external shocks, political actors need to deal with two types of uncertainty. First, external shocks do not only change actors' policy preferences, but also bring new issues on which actors' preferences are unknown into a policy sector,. Actors therefore suffer from behavioral uncertainty (Fink and Harms 2012; Krishnan et al. 2006) with respect to preferences of other actors. Second, given that external shocks increase the pressure for developing new policies (see Grossmann 2012 on "do something"), actors have to deal with policy uncertainty, i.e. uncertainty with respect to implications and effects of potential new policies (Krishnan et al. 2006; Metz and Ingold 2014).

This article analyzes the collaboration networks among collective political actors in two subsequent policy processes in Swiss energy policy. First, the policy process on the new law on nuclear energy that took place between 1998 and 2003 evolved in a context of relatively low uncertainty. Second, the policy project of the "Energy Strategy 2050" started after the Fukushima accident in 2011, and includes Switzerland stepping out of nuclear energy production and increasing its energy efficiency as well as energy supply from renewable sources. This policy process might lead to major policy change in Swiss energy policy, where nuclear energy has traditionally played an important role (Kriesi and Jegen 2001; Sager 2014). It therefore involves high behavioral and policy uncertainties for actors. Studying the collaboration networks in these two processes within the same policy sector allows for assessing whether actors behave differently depending on the degree of uncertainty a policy process has to deal with. I rely on exponential random graph models (ERGMs) in order to uncover factors accounting for the collaboration behavior of actors.

The reminder of the article is structured as follows. In the theoretical part, I first discuss both types of uncertainties. I then formulate hypotheses about the differences between actors' collaboration behavior depending on whether a process involves more or less uncertainty. Subsequently, I describe the case, data, and methods. Results of the ERGM are discussed before presenting conclusions and policy implications. 


\section{Methods}

\subsection{Shocks and uncertainty in policy processes}

External shocks provide both collective political actors and the general public with new evidence on a given issue or a policy; alternately, they influence the emphasis both the public and collective actors put on given aspects of an issue. They can therefore change actors' preferences on existing as well as new issues, and potentially change the image of a policy (Baumgartner and Jones 1993; Hall 1993; Sabatier and Jenkins-Smith 1993).

External shocks and changing policy images create uncertainty, which can be defined as limited knowledge about future, past, or current events (Walker et al. 2013). Several interdependent types of uncertainty can be distinguished (Newig et al. 2005; Sigel et al. 2010). This article focuses on behavioral and policy uncertainty. Behavioral uncertainty relates mostly to limited knowledge about current events. It refers to the difficulties actors experience when they try to anticipate the preferences of other actors with respect to both existing and new issues (Fink and Harms 2012; Krishnan et al. 2006). In any policy process, actors usually lack the complex knowledge of all current and future institutions, of the interconnectedness of others' decisions, and of the strategies and preferences adopted by others (Lubell 2013). However, there is arguably more behavioral uncertainty if some actors are about to change their preferences, and if new issues are dealt with in a policy process (Weible 2008: 626). In such situations, actors are themselves uncertain about which norms to follow (Newig et al. 2005), and anticipating the preferences of others is thus even more complicated. Policy uncertainty also relates to new evidence, issues, and preferences, but describes limited knowledge about the future. Under the conditions of policy uncertainty, the choice of policy instruments is complicated, as the effects of choosing one instrument over another are not clear (Landry and Varone 2005). Actors suffer from substantive knowledge deficits (Newig et al. 2005), and have a hard time recoginzing "the links between actions and 
consequences" (Weible 2008: 626). They are thus uncertain with respect to their choice of policy instruments, and the potential effects of introducing new policy instruments or abandoning old ones (Aoki 2007; Arentsen et al. 2000; Krishnan et al. 2006; Metz and Ingold 2014).

\subsection{Collaboration in policy processes}

Collective political actors such as political parties, interest groups, or administrative agencies in democratic systems need to collaborate with others in order to get access to information and resources, influence decision-makers, coordinate their activities, set up advocacy coalitions, and thereby achieve their policy preferences. It has been shown that a) actors with similar preferences tend to collaborate (Henry 2011; Weible 2005; Weible and Sabatier 2005; Zafonte and Sabatier 1998), b) actors are power driven and tend to collaborate with others they see as influential (Henry 2011; Stokman and Zeggelink 1996), c) actors tend to establish collaboration relationships along pre-existing and trusted contacts (Berardo 2009; Leifeld and Schneider 2012), and d) given types of actors - for example, state actors in Europeanized policy processes - have specific incentives for establishing collaboration relations (Fischer and Sciarini 2013).

This paper innovates by taking into account the context of uncertainty, which I anticipate will interact with these classical drivers of collaboration. Both behavioral and policy uncertainty affect the incentives of actors when looking for collaboration partners.

First, under conditions of behavioral uncertainty, actors are unsure about the policy preferences of potential collaboration partners. Due to the external shock, new issues and policy instruments are discussed, about which actors' preferences are unknown. Furthermore, actors might have changed their preferences with respect to existing issues due to the external shock. Under conditions of uncertainty, actors have a harder time recognizing preference similarity and using this information as a basis for establishing collaboration. Therefore, 
higher behavioral uncertainty in a policy process corresponds to a lower importance of preference similarity.

Hypothesis 1: An increase in behavioral uncertainty is inversely proportional to the importance of preference similarity for the establishment of collaboration.

Second, given the difficulties of anticipating preferences of potential collaboration partners, actors search for information on the (new) preferences of other actors. Finding out about (new) preferences of potential collaboration partners is easiest for actors which are of the same organizational type (Carpenter et al. 2004: 225). Actors of the same type know about the organizational functioning of their peers, tend to be active in the same institutional venues, and have access to similar type of information. For example, whereas political parties are mostly active in Parliament, interest groups participate in the policy process within hearings or working groups. Actors thus have an easier time gathering new information on preferences of actors of their own type than on actors of a different type. Such phenomena of actor type homophily when establishing ties are common in social networks of any kind (Gerber et al. 2013; McPherson et al. 2001; Scholz et al. 2008).

Hypothesis 2: An increase in behavioral uncertainty is proportional to the importance of actor type homophily for the establishment of collaboration.

Third, under conditions of behavioral uncertainty, actors seek to establish collaboration relationships with others they can trust. More specifically, having common acquaintances helps actors to reduce the uncertainty about other actors (Berardo 2009; Berardo and Scholz 2010; Carpenter et al. 2004; Leifeld and Schneider 2012). When an actor decides whether to establish a collaboration with another actor, relying on contacts of existing collaboration partners increases confidence that collaboration efforts will be rewarding (Leifeld and 
Schneider 2012). Berardo and Scholz (2010) argue that actors seek "bonding relations" when uncertainty about the behavior of other actors and risks of defection are high.

Hypothesis 3: An increase in behavioral uncertainty is proportional to the importance of existing indirect collaboration for the establishment of collaboration.

As opposed to behavioral uncertainty, policy uncertainty refers to uncertainty with respect to the effects of potentially new policy instruments. In a situation of policy uncertainty, actors are supposed to collaborate with three types of actors. First, in the struggle against uncertainty about the effects of different policy instruments, actors seek information from scientific experts (Klein et al. 1999; Leach et al. 2013; Newig et al. 2005). Political actors need to increase their knowledge about the problem at hand, the available options of policy instruments, and the likely effects of the different policy instruments on target groups of the policy. Knowledge about these elements is an important resource in political discussions, as actors use them to justify their own preferences.

\section{Hypothesis 4: An increase in policy uncertainty is proportional to the popularity of} scientific actors as collaboration partners.

Second, policy uncertainty can be reduced by including the target groups of the policy in the policy process (Newig et al. 2005). Target groups are actors which are directly affected by given policy instruments, i.e. they are the expected "winners" or "losers" of a policy process (Kim et al. 2015). Target groups can act as information providers to policy makers who lack detailed knowledge about the ramifications of policies (Beyers 2004; Bouwen 2002; Gullberg 2013). In the specific case of nuclear energy, target groups are actors advocating or producing alternative energy on the one hand, and advocates and producers of nuclear energy on the other. Anti-nuclear groups and representatives of alternative energy were the losers of the first policy process in 2003 , as only incremental changes were made to the existing policy which 
was strongly based on nuclear energy production. They tend to be the winners of the 2013 project, which supports alternative energy sources. Pro-nuclear groups can be identified as the winners of the first process and the losers of the second process.

Hypothesis 5: An increase in policy uncertainty is proportional to the popularity of target groups of the respective policy projects as collaboration partners.

\subsection{Energy policy in Switzerland}

Energy policy has been a historically controversial subject in Switzerland. For over 30 years, so-called pro-economy and pro-ecology coalitions have been opposing each other along roughly similar conflict lines (Fischer 2012; Jegen 2003; Kriesi 2011; Kriesi and Jegen 2001). A pro-economy coalition, mainly comprised of business organizations and center-right parties, defends free market principles and low energy prices (Kriesi and Jegen 2001). A proecology coalition is comprised of left and green parties as well as environmental organizations. It is mainly concerned with the environmental impact of nuclear energy. The first policy process under study started in 1998, when the policy project was prepared by the federal administration. In 1999, two popular initiatives asked for a 10 year moratorium on permissions to build new nuclear power plants and for a step-wise phasing out of nuclear energy, respectively. The government and its administration then adapted the ongoing project and transformed it into a counter-proposal to the initiatives. This counter-proposal in the form of a new law on nuclear energy essentially enabled the replacement of the existing nuclear power plants. In 2003, both popular initiatives were rejected by the population, and the new law on nuclear energy came into force. The law provides no time limitation for existing nuclear power plants, but includes the possibility that licenses can be limited. New plants can be built, but the provision of licenses for new power plants and geological repositories is subjected to a facultative referendum. Furthermore, the law provides a 10 year moratorium on 
the exportation of nuclear waste for reprocessing. While some concerns of the opponents of nuclear energy were taken into account, the output of this policy process essentially reiterated the existing, pro-nuclear policy (Fischer 2012). ${ }^{1}$ Of course, policy change was not excluded from the beginning, as the two popular initiatives for phasing out of nuclear energy illustrated. Yet, the policy context was stable, and there was no sense of urgency due to an external shock. This policy process lasted for six years.

The second policy process under study started in 2011, and is still ongoing. The nuclear accident in Fukushima led to a worldwide discussion on the safety of nuclear power and had a crucial influence on the public image of nuclear energy policy. For example, the accident decreased the acceptance of nuclear energy production among the general public in Switzerland (Siegrist et al. 2014; Siegrist and Visschers 2013) as well as in many other countries (Kim et al. 2013). Given that national elections were scheduled in Switzerland for fall 2011, collective actors, and more specifically political parties, had an incentive to adapt their position to the public opinion. Based at least partly on the changing public opinion, the new positions of collective political actors, and the sense of urgency, the Swiss government quickly decided that Switzerland would abandon the production of nuclear energy and elaborated a new policy project called the "Energy Strategy 2050". According to the governmental project, the five nuclear power plants in Switzerland need to be switched off at the end of their official running period, and the building of new power plants will not be allowed in the future. In order to cope with this decision, the Swiss energy system needs to be adapted to be able to replace the power generated by the five existing nuclear power plants. The "Energy Strategy 2050" aims to increase the production of renewable energy, mainly hydropower, wind power, or photovoltaic energy production, by subsidizing these alternative energy sources. However, the exploitation of alternative energy sources is unable to meet the demand for energy in full. Switzerland therefore also needs to increase its production of energy from fossil sources such as gas or combined heat and power technologies. The first 
package of measures of the Energy Strategy 2050 includes measures on energy efficiency, renewable energies, fossil energy plants, and electricity grids (Federal Council 2013). The Energy Strategy 2050 has been discussed since the end of 2014 in Parliament, which tends to follow the governmental project on the most important points. While there is uncertainty in any policy process (Lubell 2013), one can reasonably argue that both behavioral and policy uncertainty were higher in the 2013 process than in the 2003 process. Note that the distinction between high and low uncertainty is based on the author's in-depth knowledge of the case. Alternative and complementary strategies of assessing levels of uncertainty, not used in this study, would be to rely on media coverage, legislative activity, the perception of survey respondents, or opinion polls. Also, while an absolute level of uncertainty is difficult to assess, the argument in this paper is based on a relative difference of uncertainty between the two processes.

Given the external shock of the Fukushima accident and the subsequent and quick governmental decision on nuclear phase-out, both behavioral and policy uncertainty were much higher in the second process than in the first one. First, the 2013 policy process unfolded after one of the biggest nuclear accidents in history, whereas no external preceded the 2003 process. Whereas the preferences of political actors on the issue of nuclear energy were traditionally stable and publicly known, including during the 2003 process, one could reasonably assume that the Fukushima accident would lead some actors to revise their preferences. Furthermore, new issues such as subsidies for renewable energies, on which actors' preferences after the external shock were unclear, were discussed. Actors thus had a more difficult time recognizing the policy preferences of other actors, which might have changed due to the crisis. Behavioral uncertainty, i.e. uncertainty about other actors' preferences, was thus higher in 2013 than in 2003. Second, shortly after the Fukushima accident, at the very beginning of the 2013 policy process, the Swiss government announced the phasing out of nuclear energy. This meant that new policy instruments for the support of 
alternative energy production would have to be discussed. This created policy uncertainty. In contrast, no major new policy instruments were discussed during the 2003 process.

\subsection{Data}

In order to identify the main collective actors involved in both policy processes, I used the classic combination of positional, decisional, and reputational approaches (see e.g. Knoke 1993: 30). Following the decisional approach, I identified the actors that took part in the different venues (e.g. expert committees, consultation procedure, parliamentary committees, etc.) of the respective policy processes. I added actors holding an overall strategic position in the Swiss political system (positional approach) to this list. Finally, in accordance with the reputational approach, I asked actors during the interviews / surveys to add important actors to the initial list of actors (reputational approach). However, no additional actor was mentioned more than twice. This resulted in a list of 24 actors for the 2003 process on the law on nuclear energy, and a list of 65 actors for the 2013 process on the Energy Strategy 2050. Actors were identified through an identical procedure, and 12 actors are present in both datasets. Both datasets contain the most important actors in Swiss energy politics in the respective time periods. Furthermore, while the actors themselves are not always the same, the same types of actors are present in both policy processes. For example, while WWF (World Wildlife Fund) represents environmental interests in the first process, Pro Natura plays this very same role in the second process. Data on the policy process on the law on nuclear energy between 1999 and 2003 was gathered in 2008 through face-to-face interviews with representatives of the collective actors. ${ }^{2}$ Data on the policy process on the Energy Strategy 2050 was gathered in early 2014 through a postal survey. The response rate for the interviews was $100 \%$, and the response rate for the postal survey was $72 \%$, resulting in a set of 44 actors for the 2013 process. ${ }^{3}$ The higher number of actors in the second process is due to the broader set of issues 
the process dealt with (i.e. nuclear energy, renewable energy and energy efficiency instead of mainly nuclear energy). The list of actors appears in the appendix.

The outcome network comprises directed collaboration ties among the collective political actors involved in the respective policy processes. To identify the collaboration network among actors, I asked our interview partners and survey respondents to indicate, drawing from a list of actors that participated in the respective policy process, those actors with whom they had collaborated intensely, i.e. with whom they had frequent contact without necessarily agreeing on the substantive policy issue at stake. ${ }^{4}$ Table 1 provides some descriptive statistics for both collaboration networks. Not surprisingly, given the larger set of actors in the second process, the density of the collaboration network is higher in the process on the law on nuclear energy (0.28) than in the process on the Energy Strategy 2050 (0.18). On average, actors have 6.5 collaboration ties in 2003 and 8 in 2013 . Whereas $44 \%$ of the ties are reciprocated in the earlier process, $36 \%$ of ties are reciprocated in the latter process. With respect to the basic network structure, both networks are similar and therefore comparable.

\section{--- Table 1 about here ---}

For hypotheses testing, I rely on the following operationalization of independent variables in the ERGMs. First, like the data on collaboration, the measure of preference similarity is based on interview and survey data. Actors were asked to select, from the same list of actors mentioned above, those actors with whom they had converging or diverging preferences on the policy project. ${ }^{5}$ This information is represented as a network whose ties express preference similarity (1) or preference dissimilarity (-1) and is added to the model as an edge covariate term. Second, four actor types (state actors, political parties, interest groups, others) are identified. A nodematch term measures the tendency of actors to collaborate with other actors of the same type. Third, the endogenous network effect of transitivity serves as an 
indicator for the importance of trust as a factor explaining the establishment of collaboration ties between actors. The GWESP (geometrically weighted edgewise shared partner) and GWDSP (geometrically weighted dyadwise shared partner) measure transitivity. The GWDSP captures the tendency of a pair of actors (collaborating or not) to have a shared collaboration partner (corresponding to either open or closed triangles), whereas the GWESP measures whether two actors that collaborate do have shared partners (corresponding to closed triangles). ${ }^{6}$ Fourth, in order to examine the specific activity and popularity of scientific actors and target groups of energy policy, a node covariate is introduced for the respective actor types. Scientific actors are research institutes, universities, as well as individual experts and their professional associations ( 3 in 2003, 4 in 2013). The category of representatives of alternative energy is comprised of professional associations of different types of renewable energy producers, natural protection associations, and green parties (5 in 2003, 8 in 2013). The group of representatives of nuclear energy is comprised of providers of nuclear energy as well as their professional associations and pro-nuclear think tanks (4 in 2003, 8 in 2013). Three additional variables measuring important drivers of collaboration in the existing literature are introduced as controls. First, the endogenous network structure of reciprocity provides information about actors' tendency to reciprocate ties. Reciprocity exists if actor b reciprocates the collaborative tie it receives from actor a. Second, a dummy variable measures formal authority. The variable differentiates state actors from non-state actors and relates to two effects in the models, i.e. state actors' outgoing ties and their incoming ties. Third, I control for the fact that actors are resource-dependent (Stokman and Zeggelink 1996) and assess which other actors they perceive as powerful. In the interviews and survey, actors were asked to indicate whom - from the same list of actors as described above - they perceived as very powerful in the respective process. The information in the resulting matrix is introduced in the model as an edge covariate term. 


\subsection{Exponential random graph models (ERGM)}

Network analysis has proven useful to analyze processes of social and political change (Fischer et al. 2012; Vantoch-Wood and Connor 2013). To evaluate the impact of both types of uncertainty on collaboration patterns between actors, I compare results of Exponential Random Graph Models (ERGM, Robins et al. 2007; Wasserman and Robins 2005) for both policy processes. ERGMs are statistical models designed for analyzing network data. Observations on networks are by definition non-independent. This means that the assumption that a collaboration tie between actors $i$ and $j$ (observation a) is independent of any other collaboration ties that actors $i$ or $j$ have with any other actor (observations $\mathrm{b}, \mathrm{c}$, etc.) is unrealistic. Standard regression models do not take this dependency into account and erroneously attribute explanatory power to exogenous independent variables, instead of attributing them to endogenous network structures such as reciprocity or transitivity (e.g. Cranmer and Desmarais 2011; Goodreau et al. 2009). ERGMs treat the whole network as a single observation and test whether the observed network is the result of a random process of tie formation, or whether specific mechanisms of tie formation account for the observed network configuration. ERGMs calculate the probability of observing a given network as compared to all networks that could have been observed, given a set of statistics on the network (Cranmer and Desmarais 2011).

ERGMs include three types of statistics, i.e. node covariates, edge covariates, and endogenous network structures. The first relate to attributes of nodes (in the present case, types of political actors); the second are attributes of ties between two nodes (i.e. preference similarity between two actors). The third type, endogenous network structures, refer to effects of network structures on the network itself (Goodreau et al. 2009: 105). An example is reciprocity, which assesses whether actors reciprocate an existing tie. ERGM coefficients can be interpreted as the change in the conditional log-odds of observing a given edge in the network with each 
unit increase in a given network statistic, the rest of the network being constant (Hunter et al. 2008).

Given the high number of possible network configurations, computation of the exact maximum likelihood is impossible. Models are thus estimated by Markov Chain Monte Carlo Maximum Likelihood (MCMC-MLE). This method approximates the exact likelihood by relying on a sample from the range of possible networks to estimate the parameters (Cranmer and Desmarais 2011). The MCMC algorithm proceeds by comparing the probability of a new, randomly selected proposed network to the current one in the chain, then deciding whether to accept the proposed network as the next step in the chain or not (Morris et al. 2008: 17). These iterations stop when the differences between some characteristics of the observed network and the sample mean are no longer significant ( $\mathrm{p}$ greater than 0.05 ).

\section{Results}

Results of the ERGMs for both processes appear in table 2. Bold values indicate statistical significance of the respective effect with a p-value of 0.05 or lower.

\section{--- Table 2 about here ---}

Three endogenous parameters are included in the models. The first is the edges parameter which controls for the number of edges in the networks, i.e. network density. It is negative in both models, indicating that actors do have a negative tendency to establish random ties. Second, the reciprocity parameter is positive in both models. This suggests that actors tend to reciprocate collaboration ties, i.e. if actor $a$ indicates collaboration with actor $b$, actor $b$ also indicates collaboration with actor $a$. The effects are of approximately the same size in both processes. The size of effects, i.e. the odds ratio of observing a collaborative tie if the independent variable increases by one unit, can be obtained by calculating the exponential 
function of effects. Thus, in the 2003 process, the probability that actor $a$ indicates collaboration with actor $b$ is $632 \%\left(6.32\right.$, i.e. $\left.\mathrm{e}^{1.99}-1\right)$ higher if actor $b$ also indicates collaboration with actor $a$, as compared to a situation where this is not the case. Third, the GWDSP and GWESP parameters indicate triadic closure. The GWDSP parameter serves as a baseline parameter. A negative GWDSP parameter means that a dyad of actors, independently of whether they collaborate or not, have a negative tendency to have shared partners. Combined with this, a positive GWESP parameter can be interpreted as a tendency of actors which are collaborating to actually have shared partners. Interpreting both parameters together, there is a clear tendency to triadic closure in the 2013 process, whereas this is not the case in the 2013 process.

Actor type attributes are used to measure the popularity or activity of specific nodes in the network. A positive and significant "incoming" parameter means that a given actor type is mentioned more often as a collaboration partner than would be the case in a random network, which can be interpreted as popularity. A positive and significant "outgoing" parameter can accordingly be interpreted as a specific activitiy in the collaboration network. In 2003, scientific actors, representatives of alternative energy and state actors are especially popular as collaboration partners. For example, being a state actor, as compared to any other type of actor, increases the probability of being mentioned as a collaboration partner by $447 \%$ ( 4.47 , i.e. $\left.\mathrm{e}^{1.70}-1\right)$ in the 2003 policy process. State actors and nuclear energy representatives are especially popular in 2013, whereas scientific actors are unpopular as collaboration partners in the 2013 process. Nuclear energy actors are particularly active, and scientific actors are very inactive in the earlier process. For example, being a scientific actor in the 2003 process, as compared to any other actor, decreases the probability of collaborating with other actors by $101 \%\left(1.01\right.$, i.e. $\left.\mathrm{e}^{0.7}-1\right)$. In 2013 , both alternative and nuclear energy representatives are highly active in establishing collaboration with others. 
The actor type homophily parameter measures whether actors of the same organizational type have a particular tendency to collaborate. For the 2013 process, the respective parameter is positive and significant, but there is no significant effect in the earlier process. Finally, two variables are measured on the dyadic level: First, the perceived power of a potential collaboration partner is a simple control variable. Its effect is positive and of about the same size in both models, meaning that actors tend to collaborate with those actors they perceive as powerful (Ingold and Fischer 2014). Second, preference homophily is also an important predictor of collaboration in both periods. Yet, the respective coefficient is 1.70 in the model of the 2003 process, but only 1.18 in the model on the 2013 process. Thus, the probability that two actors collaborate increases by $447 \%\left(4.47\right.$, i.e. $\left.\mathrm{e}^{1.70}-1\right)$ if they have similar preferences in 2003. In the network on the 2013 process, the probability that two actors collaborate increases by $225 \%\left(2.25\right.$, i.e. $\left.\mathrm{e}^{1.18}-1\right)$ only if they have similar preferences. ${ }^{7}$

\section{Discussion}

Hereafter, I first discuss the results in light of the hypotheses, and then deduce some policy implications from the results. Hypotheses can be supported if the effect is significant in one network but not in the other (in agreement with the hypothesis), or if both effects are significant, but one is clearly stronger than the other (in agreement with the hypothesis). I first discuss the three hypotheses dealing with the influence of behavioral uncertainty on the collaboration patterns of political actors. First, actors were expected to rely less strongly on preference homophily in a situation of uncertainty. As mentioned above, the preference homophily term is positive and significant in both processes. Still, hypothesis 1 can be partly supported, as the effect of preference homophily is weaker in the 2013 process evolving under uncertainty. Results clearly support hypothesis 2 . In situations of behavioral uncertainty, actors tend to turn to actors of the same type for collaboration (actor homophily), while they have no particular tendency to do so in the 2003 process. During the policy process of the 
Energy Strategy 2050, political parties tend to collaborate with political parties, interest groups with interest groups, and so on. In a situation of behavioral uncertainty, when actors need to learn about the preferences of others, turning to actors of similar organizational type appears to be a secure and rewarding strategy. Actors of the same type are often active within specific venues of a policy process (i.e., political parties in parliamentary committees, interest groups in hearings, etc.) and have similar logics of internal organization and similar roles in the policy process. According to hypothesis 3, actors are expected to collaborate with other actors they are already indirectly related to in order to deal with behavioral uncertainty. This expectation is borne out by the data. In the models for the 2003 process, evolving in a rather certain and stable context, triadic closure does not seem to play a role. Both the GWESP and GWDSP parameters are non-significant in the collaboration network of the process on the law on nuclear energy. On the contrary, both parameters are significant in the model on the collaboration network of the policy process on the Energy Strategy 2050. I now turn to the hypotheses pertaining to policy uncertainty. According to hypothesis 4, scientific actors should be especially popular as collaboration partners in processes influenced by policy uncertainty. Scientific actors behaved as generally expected in the 2003 process: They are especially popular as collaboration partners, and they are less active than others. This corresponds to the fact that the major goal of scientific actors in policy processes is often not to influence the policy output according to given preferences, but to deliver expertise and find a technically satisfying solution (Ingold and Gschwend 2014). According to hypothesis 4, this pattern should be even stronger in the 2013 process which evolved under higher uncertainty, as in such a situation other actors should tend to gather information from scientific actors. However, contrary to what was expected, scientific actors are less popular than others in the 2013 process. A possible explanation for this result is that in the 2013 policy process, political actors needed to quickly "do something" to react on the crisis 
(Grossmann 2012), and that there was no time for a proper, scientific discussion on the issue (see Ahrari 1987 for a similar interpretation of US synthetic fuels policy).

According to hypothesis 5, potential target groups of a policy process should be specifically important collaboration partners for other actors under conditions of policy uncertainty. In the case of energy policy, and in the context of prioritizing either nuclear or alternative energy, target groups are the producers and advocates of nuclear and alternative energy, respectively. Yet, results lend only partial support to this expectation. First, and contrary to the earlier process, alternative energy representatives are not especially popular as collaboration partners in the 2013 process. Second, actors representing nuclear energy interests are indeed popular as collaboration partners during the 2013 policy process on the Energy Strategy 2013. Given that the major goal of this policy process is to ban nuclear energy, actors aim to collaborate with the producers and advocates of nuclear energy production. These are expected losers of the policy process (Kim et al. 2015), and actors contacted them in order to evaluate the feasibility and acceptance of the new policy.

Whereas only producers and advocates of nuclear energy production were contacted by other actors as target groups of nuclear energy policy, both nuclear energy producers and producers and advocates of alternative energy sources were actively collaborating with other actors. The former were particularly active in the both processes, and the latter were particularly active in looking for collaboration in the 2013 process on the Energy Strategy 2050. Reaching out to other actors for collaboration is a way to influence the policy process according to one's preferences. Given the potential economic benefits or risks for their respective industry sectors, both advocates of nuclear and alternative energy were rent-seeking (Krueger 1974; Buchanan et al. 1980), and thus engaged in lobbying activities. ${ }^{8}$ Several policy implications can be deduced from these results. First, results suggest that in a context of uncertainty, actors have a harder time building stable coalitions with like-minded actors, but rather rely on collaboration contacts with other actors they know from mututal 
contacts or institutional arenas. Given that similar policy preferences are the most important criteria for actors to build coalitions, this finding has important consequences. On the one hand, policy-makers might be well advised to foster trust and knowledge by creating institutional opportunities which allow actors to exchange their views and mutually learn about their preferences. On the other hand, the fact that similar policy preferences are less important for collaboration could also represent new opportunities to policy-makers. If collaboration is guided by trust and knowledge and less by policy preferences, this might allow actors to forge compromises and elaborate mutually acceptable policy solutions. Furthermore, the finding that actors do not turn to scientific representatives in a situation of uncertainty indicates that the important exchange between scientific representatives and other actors in policy processes might suffer from a quick "do something” reaction (Grossmann 2012).

\section{Conclusions and policy implications}

Energy shocks have consequences on different levels. They influence the behavior of the population and the public image of a technology; they can lead to policy change and affect the behavioral patterns of collective political actors in a policy sector. This analysis focused on the latter and examined collaboration relations between collective actors in two subsequent policy processes, the first with lower, the second with higher uncertainty. Studying actors' collaboration patterns in policy processes is crucial for understanding the production of policy outputs. Yet, collaboration depends on the incentives provided to actors by the specific context of the policy process. After an external shock, actors suffer from two types of uncertainties, i.e. behavioral uncertainty and policy uncertainty.

Results mostly support the hypotheses with respect to how actors deal with behavioral uncertainty, i.e. uncertainty with respect to the preferences of other actors in the policy sector. First, preference similarity plays less of a role as a predictor of collaboration under conditions 
of behavioral uncertainty. If actors have a hard time recognizing the preferences of potential collaboration partners, their ability to rely on this information to establish collaboration is compromised. Second, actors under conditions of behavioral uncertainty rely on contacts with actors of the same type. Actors of the same type tend to have similar organizational logics and be active in the same venues, which fosters mutual knowledge and allows them to learn on other actors' preferences. Third, actors establish collaboration relationships with other actors they are already indirectly related to. Given the existing indirect relation, actors can trust that the new collaboration contact will be worth the effort. Results regarding the hypotheses on the behavior of actors in order to cope with policy uncertainty are less straightforward. First, in a context of uncertainty, actors do not seek collaboration with scientific actors more than in more stable environments. It seems that in situations of crisis, when political actors need to "do something (Grossmann 2012), there is simply no time for actors to deal with complex, scientific arguments. Second, whereas actors search for collaboration with representatives of nuclear power interests in a context of uncertainty, there are no specific collaboration efforts towards actors producing or advocating for renewable energy. Given that the policy change elaborated during the 2013 process is meant to ban nuclear energy in Switzerland, this indicates a specific attempt to include the potential losers in the process in order to avoid further opposition from that side. This seems especially important in the Swiss context, as losers of a policy process have the possibility to challenge a parliamentary decision by referendum.

The strongly developed instruments of direct democracy in Switzerland, such as the referendum or the popular initiative, are also important when it comes to generalization of results. While the relations between external shocks, types of uncertainties and actors' behavior should in principle also hold in other institutional contexts, it is true that the Swiss public could force political actors to "do something" (Grossmann 2012) by submitting a popular initiative. 
While results confirm most of the theoretical expectations, the research design is admittedly not perfect. Uncertainty is introduced as a context condition on the process level only, whereas measuring it at the level of actors might be an alternative, promising strategy to assess its effects. The comparison between two processes controlled for a maximum of other context factors which could have caused the differences. The statistical model controls for the different network size and densities, and both processes are dealing with the same policy sector in the same country.

Furthermore, the findings presented here have policy implications beyond Swiss energy policy. Energy policy in many other countries is increasingly influenced by uncertainty. Independently of the Fukushima accident, many countries aim to steer their energy systems towards more renewable types of energy production. Uncertainties and complexities related to climate change and international conflicts are expected to influence energy policy-making in many countries in the future. The specificities of collaboration patterns under conditions of uncertainty can have both advantages and disadvantages. On the one hand, policy-making might be complicated in the absence of stable coalitions with clear policy preferences. On the other hand, collaboration based on trust and mutual knowledge rather then similar preferences could also open up opportunities for broad compromises.

\footnotetext{
${ }^{1}$ On average, the interview partners (see data section) considered the output of the policy process on the new law on nuclear energy to be much closer to the status quo than to major policy change. Among the 11 most important policy processes in Swiss politics between 2001 and 2006, the law on nuclear energy was rated as bringing the least change to the respective policy sector (Fischer 2014).

${ }^{2}$ Only actors that participated in at least one other venue in addition to the very open consultation procedure were interviewed. Most of the interviews were conducted between February and July 2008.

${ }^{3}$ Actors who did not participate in the survey a) responded that they were only marginally involved in the policy process, b) were actors with only a technical but no political role (national commissions for nuclear waste or nuclear security), or c) were actors of the administration who were not leading the process. None of the nonresponding actors were very important in terms of perceived power.
} 
${ }^{4}$ Exact wording of the question: "Which actors did your organization strongly collaborate with during the policy process x?" Rationales for collaboration can be the exchange of information, advice, or resources, the coordination in a coalition, or the search for access to influential actors (Weible and Sabatier 2005: 182). Given the absence of agreement in the literature on the actual content of relationship that one should focus on (Scholz et al. 2008), I deliberately refrained from specifying this content and opted instead for a broad definition of collaboration.

${ }^{5}$ Exact wording of the question: "With which actors did your organization have convergent or divergent preferences with respect to the policy process $x$ ?"

${ }^{6} \mathrm{~A}$ low geometrical weighting parameter of 0.1 for both parameters means that two actors are unlikely to have a lot of shared partners and avoids model degeneracy (Goodreau et al. 2008; Leifeld and Schneider 2012; Morris et al. 2008).

${ }^{7}$ An additional control variable in the 2013 model, accounting for the 2003 collaboration ties, has no significant effect on the 2013 collaboration network and does not affect the other results. Furthermore, leaving out any of the attribute variables (science, state, nuclear and alternative interests) does not affect the results.

${ }^{8}$ Note however that a more specific test on whether the lobbying attempts were specifically directed at state actors (by including an edge covariate for all nuclear energy / alternative energy - state actor dyads) does not yield siginificant results. 


\section{Acknowledgements}

The author would like to thank Sandrine Bossy, Karin Ingold, Lorenz Kammermann, David Keller, Guenda Malinverni, Chantal Strotz, Pascal Sciarini and Denise Traber for help with the data gathering and research design, and Karin Ingold and Jennifer Victor for helpful comments on an earlier version. Parts of the data for this analysis stem from a research project sponsored by the Swiss Science Foundation (Grant No. 100012-113964).

Word count: 7393 


\section{References}

Ahrari, M. E., 1987. A Paradigm of 'Crisis' Decision Making: The Case of Synfuels Policy. Brit J Polit Sci 17 (01): 71-91.

Aoki, M., 2007. Endogenizing institutions and institutional changes. J Inst Econ 3 (1): 1-31.

Arentsen, M. J.,Bressers, H.Th.A., O'toole, L. J.,. 2000. Institutional and Policy Responses to Uncertainty in Environmental Policy: A Comparison of Dutch and U.S. Styles. Policy Stud J 28 (3): 597-611.

Baumgartner, F., Jones, B.D., 1993. Agendas and Instability in American Politics. Chicago: The University of Chicago Press.

Berardo, R., 2009. Generalized Trust in Multi-organizational Policy Arenas: Studying Its Emergence from a Network Perspective. Polit Res Quart 62 (1): 178-89.

Berardo, R., Scholz, J.T., 2010. Self-Organizing Policy Networks: Risk, Partner Selection and Cooperation in Estuaries. Am J Polit Sci 54 (3): 632-49.

Berardo, R., 2013. The Coevolution of Perceptions of Procedural Fairness and Link Formation in Self-Organizing Policy Networks. J Polit 75 (3): 686-700.

Beyers, J., 2004. Voice and Access. Political Practices of European Interest Associations. Eur Union Polit 5 (2): 211-40.

Bouwen, P., 2002. Corporate lobbying in the European Union: the logic of access. $J$ Eur Public Policy 9 (3): 365-90.

Buchanan, J. M., Tollison, R. D., Tullock, G., 1980. Toward a theory of the rent-seeking society: Texas A \& M Univ Pr.

Federal Council. 2013. Botschaft zum ersten Massnahmenpaket der Energiestrategie 2050 (Revision des Energierechts) und zur Volksinitiative «Für den geordneten Ausstieg aus der Atomenergie (Atomausstiegsinitiative)»».

Carpenter, D. P., Esterling, K.M., Lazer, D.M., 2004. Friends, Brokers, and Transitivity: Who Informs Whom in Washington Politics? J Polit 66 (1): 224-46.

Cranmer, S.J., Desmarais, B.A., 2011. Inferential Network Analysis with Exponential Random Graph Models. Polit Anal 19: 66-86.

Fink, M., Harms, R., 2012. Contextualizing the relationship between self-commitment and performance: Environmental and behavioural uncertainty in (crossborder) alliances of SMEs. Entrep Region Dev 24 (3-4): 161-79.

Fischer, M., 2012. Entscheidungsstrukturen in der Schweizer Politik zu Beginn des 21. Jahrhunderts. Zürich/Chur: Verlag Rüegger. 
Fischer, M., Ingold, K., Sciarini, P., Varone, F., 2012. Impacts of Market Liberalization on Regulatory Network: A Longitudinal Analysis of the Swiss Telecommunications Sector. Policy Stud J 40 (3): 435-57.

Fischer, M., Sciarini, P., 2013. Europeanization and the inclusive strategies of executive actors. J Eur Public Policy 20 (10): 1482-98.

Fischer, M., 2014. Coalition Structures and Policy Change in a Consensus Democracy. Policy Stud J 42 (3): 344-66.

Gerber, E.R., Henry, A.D., Lubell, M., 2013. Political Homophily and Collaboration in Regional Planning Networks. Am J Polit Sci 57 (3): 598-610.

Goodreau, S.M., Handcock, M.S., Hunter, D.R., Butts, C.T., Morris, M., 2008. A statnet Tutorial. J Stat Softw 24 (9): 1-26.

Goodreau, S.M., Kitts, J.A., Morris, M., 2009. Birds of a feather, or friend of a friend? Using exponential random graph models to investigate adolescent social networks. Demography 46 (1): 103-25.

Grossman, P.Z., 2015. Energy shocks, crises and the policy process: A review of theory and application. Energ Policy 77 (0): 56-69.

Grossmann, P.Z., 2012. The logic of deflective action: US energy shocks and the US policy process. J Public Policy 32 (1): 33-51.

Gullberg, A.T., 2013. Pressure or Information? Lobbying for Binding Renewable Energy Targets in the European Union. Rev Policy Res 30 (6): 611-28.

Hall, P.A., 1993. Policy Paradigms, Social Learning, and the State: The Case of Economic Policymaking in Britain. Comp Polit 25 (3): 275-96.

Henry, A.D., 2011. Ideology, Power, and the Structure of Policy Networks. Policy Stud J 39 (3): 361-83.

Hunter, D.R., Handcock, M.S., Butts, C.T., Goodreau, S.M., Morris, M., 2008. ergm: A Package to Fit, Simulate and Diagnose Exponential-Family Models For Networks. $J$ Stat Softw 24 (3): 1-29.

Ingold, K., 2011. Network Structures within Policy Processes: Coalitions, Power, and Brokerage in Swiss Climate Policy. Policy Stud J 39 (3): 435-59.

Ingold, K., Fischer, M., 2014. Drivers of collaboration to mitigate climate change: An illustration of Swiss climate policy over 15 years. Global Environ Chang 24: 88-98.

Ingold, K., Gschwend, M., 2014. Science in Policy Making: neutral experts or strategic policymakers? West Eur Polit 37 (5): 993-1018. 
Jegen, M., 2003. Energiepolitische Vernetzung in der Schweiz: Analyse der

Kooperationsnetzwerke und Ideensysteme der energiepolitischen

Entscheidungsträger. Basel/Genf: Helbling und Lichterhahn.

Kim, E., Urpelainen, J., Yang, J., 2015. Eletric utilities and American climate policy: lobbying by expected winners and losers. J Public Policy First View Article.

Kim, Y., Kim, M., Kim, W., 2013. Effect of the Fukushima nuclear disaster on global public acceptance of nuclear energy. Energ Policy 61 (0): 822-28.

Klein, R.T., Nicholls, R., Mimura, N., 1999. Coastal Adaptation to Climate Change: Can the IPCC Technical Guidelines be applied? Mitigation and Adaptation Strategies for Global Change 4 (3-4): 239-52.

Knoke, D., 1993. Networks of Elite Structure and Decision Making. Sociol Method Res 22 (1): $22-45$.

Kriesi, H., Jegen, M., 2001. The Swiss energy policy elite: The actor constellation of a policy domain in transition. Eur J Polit Res 39: 251-87.

Kriesi, H., 2011. Switzerland. In Wolfgang Müller, ed. Phasing-out and Phasing-in: The Comparative Politics and Policies of Nuclear Energy in Western Europe.

Krishnan, R., Martin, X., Noorderhaven, N.G., 2006. When does trust matter to alliance performance? Acad Manage J 49 (5): 894-917.

Krueger, Anne O. 1974. The political economy of the rent-seeking society. Am Econ Rev: 291-303.

Landry, R., Varone, F., 2005. The choice of policy instruments: confronting the deductive and the interactive approaches. Designing Government. From Instruments to Governance: 106-31.

Leach, W.D., Weible, C.M., Vince, S.R., Siddiki, S.N., Calanni, J.C., 2014. Fostering Learning through Collaboration: Knowledge Acquisition and Belief Change in Marine Aquaculture Partnerships. J Publ Adm Res Theor 24 (3): 591-622.

Leifeld, P., Schneider, V., 2012. Information Exchange in Policy Networks. Am J Polit Sci 53 (3): 731-44.

Lubell, M., 2013. Governing Institutional Complexity: The Ecology of Games Framework. Policy Stud J 41 (3): 537-59.

McPherson, M., Smith-Lovin, L., Cook, J.M., 2001. Birds of a Feather: Homophily in Social Networks. Annu Rev Socio 27: 415-44. 
Metz, F., Ingold, K., 2014. Policy Instrument Selection under Uncertainty: The Case of Micropollution Regulation. Paper presented at Annual Meeting of the Swiss Political Science Association. Bern, 2014.

Morris, M., Handcock, M.S., Hunter, D.R., 2008. Specification of Exponential-Family Random Graph Models: Terms and Computational Aspects. J Stat Softw 24 (4): 1-24.

Newig, J., Pahl-Wostl, C., Sigel, K. 2005. The role of public participation in managing uncertainty in the implementation of the Water Framework Directive. Eur Env 15 (6): 333-43.

Nohrstedt, D., 2005. External shocks and policy change: Three Miles Island and Swedish nuclear energy policy. J Eur Public Policy 12 (6): 1041-59.

Robins, G., Pattison, P., Kalish, Y., Lusher, D., 2007. An introduction to exponential random graph (p*) models for social networks. Soc Networks 29: 173-91.

Sabatier, P.A., Jenkins-Smith, H., (Eds.) 1993. Policy Change and Learning: An Advocacy Coalition Approach. Boulder: Westview Press.

Sager, F., 2014. Infrastrukturpolitik: Verkehr, Energie und Telekommunikation. In Peter Knoepfel, Hanspeter Kriesi, Wolf Linder, Yannis Papadopoulos and Pascal Sciarini, eds. Handbuch der Schweizer Politik. Zurich: NZZ Verlag,

Scholz, J.T., Berardo, R., Kile, B., 2008. Do Networks Solve Collective Action Problems? Credibility, Search, and Collaboration. J Polit 70 (2): 393-406.

Siegrist, M., Visschers, V.H.M., 2013. Acceptance of nuclear power: The Fukushima effect. Energ Policy 59 (0): 112-19.

Siegrist, M., Sütterlin, B., Keller, C., 2014. Why have some people changed their attitudes toward nuclear power after the accident in Fukushima? Energ Policy 69 (0): 356-63.

Sigel, K., Klauer, B., Pahl-Wostl, C. 2010. Conceptualising uncertainty in environmental decision-making: The example of the EU water framework directive. Ecol Econ 69 (3): 502-10.

Stokman, F.N., Zeggelink, E.P.H., 1996. Is Politics Power or Policy Oriented? A Comparative Analysis of Dynamic Access Models in Policy Networks. J Math Sociol 21 (1-2): 77111.

Vantoch-Wood, A., Connor, P.M. 2013. Using network analysis to understand public policy for wave energy. Energ Policy 62 (0): 676-85.

Wakiyama, T., Zusman, E., Monogan Iii, J.E., 2014. Can a low-carbon-energy transition be sustained in post-Fukushima Japan? Assessing the varying impacts of exogenous shocks. Energ Policy 73 (0): 654-66. 
Walker, W. E., Lempert, R. J., Kwakkel, J. H., 2013. Deep Uncertainty. In Gass, S.I., Fu, M.C., eds. Encyclopedia of Operations Research and Management Science. Springer US, 395-402.

Wasserman, S., Robins, G. 2005. An Introduction to Random Graphs, Dependence Graphs, and $\mathrm{p}^{*}$. In Peter J. Carrington, John Scott and Stanley Wasserman, eds. Models and Methods in Social Network Analysis. Cambridge: Cambridge University Press, 14861.

Weible, C.M., 2008. Expert-based information and policy subsystems: a review and synthesis. Policy Stud J 36 (4): 615-35.

Weible, C.M., 2005. Beliefs and Perceived Influence in a Natural Resource Concflit: An Advocacy Coalition Approach to Policy Networks. Polit Res Quart 58 (3): 461-75.

Weible, C.M., Sabatier, P.A., 2005. Comparing Policy Networks: Marine Protected Areas in California. Policy Stud J 33 (2): 181-201.

Zafonte, M., Sabatier, P.A., 1998. Shared Beliefs and Imposed Interdependencies as Determinants of Ally Networks in Overlapping Subsystems. J Theor Polit 10 (4): 473505. 
Table 1. Network descriptive statistics

\begin{tabular}{llllll}
\hline Process & $\begin{array}{l}\text { Duration of } \\
\text { process }\end{array}$ & $\begin{array}{l}\text { Number of } \\
\text { actors }\end{array}$ & $\begin{array}{l}\text { Density of } \\
\text { collaboration } \\
\text { network }\end{array}$ & $\begin{array}{l}\text { Average } \\
\text { number of } \\
\text { ties per } \\
\text { actor }\end{array}$ & $\begin{array}{l}\text { Percentage of } \\
\text { reciprocated } \\
\text { ties / all ties }\end{array}$ \\
\hline $\begin{array}{l}\text { Law on Nuclear } \\
\text { Energy }\end{array}$ & $\begin{array}{l}1998- \\
2003\end{array}$ & 24 & 0.28 & 6.5 & 0.44 \\
$\begin{array}{l}\text { Energy Strategy } \\
\mathbf{2 0 5 0}\end{array}$ & $\begin{array}{l}2011- \\
\text { ongoing }\end{array}$ & 44 & 0.18 & 8 & 0.36 \\
\hline
\end{tabular}


Table 2. ERGM results

\begin{tabular}{|c|c|c|}
\hline & 2003 & 2013 \\
\hline \multirow[t]{2}{*}{ Edges } & -4.11 & -3.72 \\
\hline & (.61) & $(.29)$ \\
\hline \multirow[t]{2}{*}{ Reciprocity } & 1.99 & 2.03 \\
\hline & $(.42)$ & (.21) \\
\hline \multirow[t]{2}{*}{ GWESP (0.1) } & .63 & .41 \\
\hline & $(.32)$ & (.17) \\
\hline \multirow[t]{2}{*}{ GWDSP (0.1) } & -.06 & -.21 \\
\hline & $(.07)$ & $(.02)$ \\
\hline \multirow[t]{2}{*}{ Science incoming } & 1.20 & -.70 \\
\hline & $(.43)$ & $(.28)$ \\
\hline \multirow[t]{2}{*}{ Science outgoing } & -1.14 & -.43 \\
\hline & $(.50)$ & $(.26)$ \\
\hline \multirow[t]{2}{*}{ Alternative Energy incoming } & .78 & -.07 \\
\hline & (.39) & $(.21)$ \\
\hline \multirow[t]{2}{*}{ Alternative Energy outgoing } & .18 & .98 \\
\hline & $(.39)$ & (.19) \\
\hline \multirow[t]{2}{*}{ Nuclear Energy incoming } & .05 & .53 \\
\hline & (.39) & (.19) \\
\hline \multirow[t]{2}{*}{ Nuclear Energy outgoing } & .85 & .85 \\
\hline & $(.36)$ & (.18) \\
\hline \multirow[t]{2}{*}{ State actor incoming } & 1.70 & .94 \\
\hline & $(.43)$ & $(.21)$ \\
\hline \multirow[t]{2}{*}{ State actor outgoing } & -.12 & -.34 \\
\hline & $(.43)$ & $(.27)$ \\
\hline \multirow[t]{2}{*}{ Actor type homophily } & -.02 & .67 \\
\hline & $(.27)$ & $(.14)$ \\
\hline \multirow[t]{2}{*}{ Perceived power } & 1.73 & 1.96 \\
\hline & $(.28)$ & (.16) \\
\hline \multirow[t]{2}{*}{ Preference homophily } & 1.70 & 1.18 \\
\hline & $(.25)$ & (.10) \\
\hline $\mathrm{AIC}$ & 408.46 & 1073.44 \\
\hline $\mathrm{BIC}$ & 473.17 & 1156.62 \\
\hline Log Likelihood & -189.23 & -521.72 \\
\hline
\end{tabular}




\section{Appendix A1. List of actors}

\begin{tabular}{|c|c|}
\hline $2003(N=24)$ & $2013(N=44)$ \\
\hline $\begin{array}{l}\text { Action Committee against Nuclear Energy of } \\
\text { Northwestern Switzerland }\end{array}$ & Action for a Reasonable Energy Policy \\
\hline Association "Strom ohne Atom" & Alpiq (energy company) \\
\hline Association of Swiss Electricity Companies & Association for Public Transport \\
\hline Canton Nidwalden & Association of Swiss Cities \\
\hline Christian Democratic Party & Association of Swiss Distribution System Operators \\
\hline Economisuisse & Association of Swiss Electricity Companies \\
\hline Evangelical People's Party & Axpo (energy company) \\
\hline Experts & BKW (energy company) \\
\hline Federal Office for Spatial Development & Bourgeois Democratic Party \\
\hline Federal Office for the Environment & Cantonal Directors of Energy \\
\hline Federal Office of Energy & Christian Democratic Party \\
\hline Green Party & Conference of Governments of Mountain Cantons \\
\hline Greenpeace & Department of Economic Affairs, Education and Research \\
\hline Liberal Democratic Party & $\begin{array}{l}\text { Department of Environment, Transport, Energy and } \\
\text { Communication }\end{array}$ \\
\hline Liberal Party & Department of Interior \\
\hline $\begin{array}{l}\text { National Cooperative for the Disposal of } \\
\text { Radioactive Waste }\end{array}$ & $\begin{array}{l}\text { Economic Association for Renewable Energy and Energy } \\
\text { Efficiency }\end{array}$ \\
\hline Paul Scherrer Institut & Economiesuisse \\
\hline Social Democratic Party & ElectroSuisse \\
\hline Swiss Association for Nuclear Energy & Federal Technical Highschool \\
\hline Swiss Employers' Association & Green Liberal Party \\
\hline Swiss Energy Foundation & Green Party \\
\hline Swiss Federation of Trade Unions & Greenpeace \\
\hline Swiss People's Party & House Owners' Association \\
\hline \multirow[t]{21}{*}{ Swisselectric } & Liberal Democratic Party \\
\hline & Nuclear Forum \\
\hline & Paul Scherrer Institut \\
\hline & Pro Natura \\
\hline & Sciencelndustries \\
\hline & Social Democratic Party \\
\hline & SuisseTec \\
\hline & Swiss Academies of Arts and Sciences \\
\hline & Swiss Academy of Engineering Sciences \\
\hline & Swiss Association for Mountain Regions \\
\hline & Swiss Association of SMEs \\
\hline & Swiss Car Association \\
\hline & Swiss Energy Foundation \\
\hline & Swiss Farmers' Association \\
\hline & Swiss Federation of Trade Unions \\
\hline & Swiss People's Party \\
\hline & Swiss Transport Association \\
\hline & Swissmem \\
\hline & SwissSolar \\
\hline & Travail.Suisse \\
\hline & WWF \\
\hline
\end{tabular}


